\title{
JEDI Events and Programming for OSM 2022
}

\author{
By Erin L. Meyer-Gutbrod
}

THE BIENNIAL Ocean Sciences Meeting (OSM) is the most extensive opportunity for members of the global ocean sciences community to come together to share knowledge, network, build and strengthen collaborations, and grow ideas. In addition to sharing progress in research, technology, and education, these meetings are a valuable opportunity to advance diversity and inclusivity in the ocean sciences community. OSM 2020 featured several successful events and sessions with these themes, and reflection on them since then has been valuable for guiding further diversity, equity, and inclusion (DEI) efforts at our home institutions and for planning future conferences (Behl et al., 2021, in this issue; Le Bras, 2021).

OSM 2022 (February 27 to March 4, 2022) will be the first hybrid meeting for this conference, featuring in-person events held in Honolulu, Hawai'i, while also offering a robust virtual participation component. The OSM 2022 theme is "Come Together and Connect." Hawaiian culture places great emphasis on the importance of bringing people together to form a cohesive unit that is stronger than any single individual. The word pilina in the Hawaiian language means connection, relationship, and association, as the seeds of the native pili grass are joined and mature together. In light of this theme, as well as the global movement to dismantle barriers to the participation of underrepresented groups, OSM 2022 will feature a series of events to educate, support, and empower a diverse and inclusive ocean science community. Although the meeting program is still developing, the titles below provide a preview of some of the JEDIthemed programs being planned for this exciting week.

\section{ESTABLISHING A SPACE FOR WOMEN OF COLOR IN OCEAN SCIENCES (VIRTUAL WORKSHOP)}

Women of Color (WOC) are statistically more likely to experience microaggressions, disrespect, mansplaining, white fragility, and cultural misappropriation in the workplace. Compared to their male counterparts, WOC are $45 \%$ more likely to leave STEM jobs. This virtual WOCshop ${ }^{\mathrm{TM}}$ (workshops developed and conducted by WOC) aims to combat these issues by providing solutions-oriented, hands-on training to address bias and social oppression. Join in to participate in dynamic groups and individual exercises, hear true anecdotes by WOC in the field, and learn how to create inclusive and equitable workplaces that welcome diverse perspectives for the future of ocean sciences. Participants in this WOCshop will leave with tools in hand to become active, effective bystanders empowered to establish A WOC Space at their respective workplaces. This WOCshop is for everyone who would like to increase the quality of experiences and the presence of WOC in ocean sciences!

\section{SPEAKING UP: HOW BYSTANDERS CAN CHANGE THE CONVERSATION IN STEM}

Ever wondered "Why didn't I say something?" after witnessing bias? Deciding whether and how to respond to bias is complicated. Attendees will learn about what motivates people to speak up, the challenges faced when doing so, and strategies for effective responding. PowerPlay Interactive Development's team of improvisational actors will provide scenarios for discussion and practicing intervention. This workshop is sponsored by a grant from the Sloan Foundation to support evaluation of bystander intervention workshops. Registrants for this workshop are expected to complete online survey materials before and after participation.

Presenter/Co-Facilitator: Stephanie A. Goodwin, PhD, President, Incluxion Works Inc. Co-Facilitator: David Kaye, MFA, Founder/ Artistic Director, PowerPlay Interactive Development, University of New Hampshire.

\section{JEDI TOWN HALL}

The Oceanography Society Justice, Equity, Diversity, and Inclusion committee will host a town hall to share news about TOS efforts to broaden participation in its membership and solicit feedback from the community. This will be interactive event where in-person and virtual participants can share ideas and help shape priorities for future JEDI initiatives. Information collected during the town hall will be shared with TOS members following the event via the TOS JEDI web page (https://tos.org/ diversity) and a synthesis of the community feedback published in Oceanography.

\section{STUDENT AND EARLY CAREER WORKSHOP}

For OSM 2022, the annual full day Sunday workshop will include sessions that focus on diversity, equity, and inclusion initiatives, environmental justice, and mental health. It will also provide the opportunity for students and early career scientists to meet and 
interact with their peers from across the fields of ocean policy and research. A limited number of tickets will be provided on a first-come, first-served basis, so be sure to register early to secure your spot for this event.

\section{RAINBOW RECEPTION}

This informal social event is an opportunity to share conversation and refreshments with fellow LGBTQIA+ ocean scientists and engineers. We hope to build community and get organized. Stop by anytime. There is no schedule. This event is intended for people who identify as LGBTQIA+, but allies can support us by spreading the word, encouraging LGBTQIA+ colleagues to attend, and staying tuned for opportunities to get involved in the future.

\section{INNOVATIVE SESSION IN11. HISTORICAL RESONANCE IN THE ATLANTIC: IMPLICATIONS FOR BLACK MARINE SCIENTISTS}

Screening of the documentary film Can We Talk? Difficult Conversations with Underrepresented People of Color: Sense of Belonging in STEM at the OSM 2020 conference initiated a discussion about the effects of systemic racism and bias in the ocean science community. The current proposed 2021 session will continue this conversation by screening content that centers the perspective of Black marine researchers, historians, and literary scholars on the ocean sciences. The meaning, materiality, and memory of the Atlantic Ocean will be central to this discussion. The film documents how the Atlantic slave trade and subsequent forms of racial exclusion on American coastlines have influenced the way Black marine scientists think about and do their work. This session will include a short screening of a segment from Kendall Moore's latest film, Decolonizing Science, followed by a panel discussion. For more Information, go to: https://www.kendallmooredocfilms.com/.

\section{TUTORIAL TT02. THIS IS NOT SERVICE: UNPACKING INSTITUTIONAL SUPPORT IN DIVERSITY EFFORTS}

In response to the racial justice movements and the widespread protests of 2020, there was increased interest in justice, equity, diversity, and inclusion (JEDI) in higher education. This tutorial's objective is to compare how different JEDI efforts can improve the experiences of marginalized individuals in geosciences, and more broadly, STEM fields. We will explore instances where institutional goals do not align with the community's needs, thus perpetuating the status quo. We will provide examples from community-based initiatives that empower historically underrepresented students and early career scientists in STEM and share resources to support the creation of similar efforts.

\section{EDUCATION AND OUTREACH SESSIONS}

ED05. Safety in Ocean Field Science: Prevention and Improved Response for Sexual and Gender Harassment This session is focused on strengthening the ocean sciences community by improving field environments for all participants and reducing harassment in the ocean sciences. The session chairs plan to present the recommendations, products, and implementation strategies that resulted from two workshops, one focused broadly on field sciences and one on ocean sciences specifically, to the OSM 2022 audience for dissemination, discussion, and feedback.

ED08. Addressing Barriers to Minoritized Scholars

Entering Internship, Fellowship, and Graduate

Programs in the Ocean Sciences

Scholars in minoritized groups including Black, Indigenous, and People of Color (BIPOC) as well as first-generation college students who seek careers in the ocean sciences face many barriers in pursuing their desired educational and career pathways. In this session, presenters will identify barriers to entry that affect underrepresented scholars and share approaches for creating more equitable processes and developing inclusive cultures where all can thrive.

\section{ED11. Global Capacity Development in Ocean Science} for Sustainable Development

Oceanography is a global science that requires human and technical capacity on a global scale. Currently, ocean science capacity is unevenly distributed around the world. This session will feature ideas and initiatives for advancing participation of scientists from under-resourced nations, or underrepresented groups in higher-resourced nations, in global observing systems and global decision-making boards. Opportunities will be given to all to delineate contributions to the United Nations Decade of Ocean Science for Sustainable Development and to share indigenous knowledge and culture. @

\section{REFERENCES}

Behl, M., S. Cooper, C. Garza, S.E. Kolesar, S. Legg, J.C. Lewis, L. White, and B. Jones. 2021. Changing the culture of coastal, ocean, and marine sciences: Strategies for individual and collective actions. Oceanography 34(3):53-60, https://doi.org/10.5670/oceanog.2021.307.

Le Bras, I. 2021. A conversation on building safe spaces for the LGBTQ+ community in the geosciences. Nature Communications 12:4058, https://doi.org/10.1038/ s41467-021-24020-z.

\section{AUTHOR}

Erin L. Meyer-Gutbrod (emgutbrod@seoe.sc.edu) is Assistant Professor, School of Earth, Ocean and Environment, University of South Carolina, Columbia, SC, USA, and is a member of the TOS JEDI Committee.

\section{ARTICLE DOI}

https://doi.org/10.5670/oceanog.2021.311 